\title{
RELAÇÕES SOCIOAMBIENTAIS E ESTRATÉGIA DE SOBREVIVÊNCIA EM RESERVA EXTRATIVISTA MARINHA EM SOURE, MARAJÓ
}

Mailson Lima Nazaré

Mestrando no Programa de Pós-graduação em Estudos Antrópicos na Amazônia, Universidade Federal do Pará. E-mail: mailsonlima@bom.com.br

\section{RESUMO}

Este trabalho analisa estratégias de sobrevivências desenvolvidas por dois jovens que passaram três (3) dias perdidos em área da reserva extrativista marinha no município de Soure no arquipélago do Marajó (Resex Soure), no ano de 2010. A Resex Soure é uma unidade de conservação na categoria uso sustentável que permite a interação entre seres humanos e o ambiente natural, possui uma extensão de 27.463,58 ha, e foi criada em 2001 pelo Governo Federal pela qual, circulam e sobrevivem diversas comunidades tradicionais como pescadores, extrativistas e de vaqueiros. Destaca-se que o arquipélago do Marajó possui a característica de clima sazonal com períodos de fortes estiagens e de chuvas intensas que deixa a região dos campos completamente alagados, desta forma como prática cultural e de interação social membros de famílias de vaqueiros que vivem na zonal rural de Soure, em períodos das fortes chuvas, deslocam-se cotidianamente pela área costeira litorânea que contém praias, para evitar as dificuldades de se transitar pelos campos alagados, fato este que levou os jovens que saíram da sede do município a se perderem. Assim sendo, em meio a este contexto o estudo orientou-se pela problemática de analisar como se estabeleceram as estratégias e relações socioambientais de sobrevivência dos jovens perdidos ao ambiente natural. Como objetivos propomos identificar os conhecimentos que contribuíram para suas sobrevivências e analisar as relações socioambientais que estabeleceram como estratégias de manutenção no ambiente natural. Como metodologia realizamos etnografia a partir de pesquisa de campo com entrevistas semiestruturadas, utilizamos ainda pesquisa bibliográfica direcionada por uma abordagem qualitativa. Entre os resultados verificamos que os jovens sobreviveram ao se adaptarem e interagirem com as dinâmicas estabelecidas pelo ambiente natural, tais como, a compreensão dos movimentos das marés, coletas frutas para se alimentar, bebendo água em raízes de vegetais, além de usarem as dunas das praias para dormiram e o vento para se protegerem de insetos. Conclui-se que por meio dos saberes socioambientais foi possível construírem estratégias de sobrevivência, o que realça a importância de se refletir 
a sobre os saberes e conhecimentos tradicionais que circulam entre as comunidades nos campos marajoaras.

PALAVRAS-CHAVE: Marajó. Sobrevivência. Ambiente Natural.

\title{
SOCIO-ENVIRONMENTAL RELATIONS AND SURVIVAL STRATEGY IN MARINE EXTRATIVIST RESERVE IN SOURE, MARAJÓ
}

\begin{abstract}
This paper analyzes survival strategies developed by two young people who spent three (3) days lost in the area of the marine extractive reserve in the municipality of Soure in the Marajó archipelago (Resex Soure), in 2010. Resex Soure is a conservation unit in the sustainable use category that allows interaction between human beings and the natural environment, it has an area of $27,463.58$ ha, and was created in 2001 by the Federal Government through which several traditional communities such as fishermen, extractivists and cowboys circulate and survive. It is noteworthy that the Marajó archipelago has the characteristic of seasonal climate with periods of strong droughts and intense rains that leaves the region of the fields completely flooded, thus as a cultural and social interaction practice members of cowboy families living in the zone Soure countryside, in periods of heavy rains, move daily through the coastal coastal area that contains beaches, to avoid the difficulties of moving through the flooded fields, a fact that has led young people who left the municipality's headquarters to get lost. Therefore, in the midst of this context, the study was guided by the problem of analyzing how the socioenvironmental strategies and relations of survival of young people lost to the natural environment were established. As objectives we propose to identify the knowledge that contributed to their survival and to analyze the socio-environmental relations that they established as maintenance strategies in the natural environment. As a methodology, we carry out ethnography based on field research with semistructured interviews. We also use bibliographic research guided by a qualitative approach. Among the results, we found that young people survived by adapting and interacting with the dynamics established by the natural environment, such as understanding the movements of the tides, collecting fruit to eat, drinking water from plant roots, in addition to using the dunes of the beaches to sleep in and the wind to protect themselves from insects. We conclude that through socioenvironmental knowledge it was possible to build survival strategies, which highlights the importance of reflecting on the traditional knowledge and knowledge that circulates among communities in the Marajoara fields.
\end{abstract}

KEYWORDS: Marajó. Survival. Natural environment. 


\section{INTRODUÇÃO}

As discussões sobre as questões ambientais ganharam destaque em função das mudanças civilizatórias anunciadas pela crise ambiental a partir da década 60, marcando a emergência de questionamentos da relação ser humano natureza (PORTO-GONÇALVES, 2011; LEFF, 2007).

Dentro desta perspectiva que desenvolvemos este trabalho que analisa estratégias de sobrevivências de jovens em área de reserva extrativista no município de Soure no arquipélago do Ilha de Marajó a partir de saberes estabelecidos por meio de suas relações socioambientais com o ambienta natural.

O município de Soure está localizado na parte leste do arquipélago com $3.051 \mathrm{~km}^{2}$ sendo banhado pelo oceano Atlântico, rio Amazonas, rio tartaruga e paracauari situado na região conhecida como campos marajoaras (CRUZ, 1987; MIRANDA NETO, 2005).

Portanto, nesta região diversas comunidades tradicionais tais como de pescadores, extrativistas e de vaqueiros desenvolvem atividades de subsistências em relações diretas com o meio ambiente.

Destaca-se que esta região possui uma diversidade de ecossistemas que propiciam existência e reprodução de diversas espécies da fauna e flora, questão esta influenciou a criação em 2001 pelo Governo Federal de uma unidade de conservação denominada de Reserva Extrativista Marinha de Soure (RESEXMAR/SOURE).

Assim, mesmo com a implementação da unidade de Conservação comunidades tradicionais continuam realizando suas práticas culturais cotidianas, entre elas o uso do espaço de áreas de praias para se locomoverem como alternativa aos campos alagados em períodos de cheias e fortes chuvas na região.

Neste sentido, a partir destas práticas culturais do uso da área que jovens ficaram por três dias perdidos na reserva extrativista, sobrevivendo por meio dos saberes e relações socioambientais.

O trabalho, trata-se de um estudo de caso, o qual realizamos por meio de um ensaio etnográfico com entrevistas semiestruturadas e pesquisa bibliográfica em meio a uma abordagem qualitativa.

Nesta perspectiva, evidencia-se a importância dos saberes ambientais desenvolvidos por comunidades tradicionais na região dos campos do arquipélago do Marajó como forma de 
dinamizar suas práticas culturais cotidianas.

\section{DESENVOLVIMENTO}

A Resexmar Soure, é uma Unidade de Conservação na categoria Uso Sustentável, com atuação no bioma marinho costeiro. Segundo o Sistema Nacional de Unidades e Conservação - SNUC, que foi constituído pela Lei $n^{\circ}$ 9985/2000, as Unidades de Conservação são classificação em:

\section{DAS CATEGORIAS DE UNIDADES DE CONSERVAÇÃO}

Art. 7o As unidades de conservação integrantes do SNUC dividem-se em dois grupos, com características específicas:

I - Unidades de Proteção Integral;

II - Unidades de Uso Sustentável.

§1o O objetivo básico das Unidades de Proteção Integral é preservar a natureza, sendo admitido apenas o uso indireto dos seus recursos naturais, com exceção dos casos previstos nesta Lei.

§2o O objetivo básico das Unidades de Uso Sustentável é compatibilizar a conservação da natureza com o uso sustentável de parcela dos seus recursos naturais. (BRASIL, 2000).

Neste sentido, a Resexmar Soure criada em 2001 pelo Governo Federal através de decreto s/n, possui uma área de abrangência entorno de 27.463,58 ha, iniciando sua jurisdição no perímetro urbano do município de Soure se estendendo até as regiões de zonas rurais do município (OLIVEIRA, 2012).

A área total da RESEX, subdividi-se em duas áreas: área 1 - na área com aproximadamente 23.929,13 ha, denominada Manguezal de Soure, no litoral de Soure, encontra-se a Ilha das Malvinas, ponta de Soure, Igarapé do Pesqueiro, rio Caju-Una, Rio Tarumã, Rio Cambu, Rego do Mirinduba e Igarapé das Malvinas. Na área 2, na parte continental de Soure, com 3.534,45 ha, encontra-se o Rio do Saco, Igarapé da Cabana, finalizando no mangue localizado nas delimitações da Fazenda Bom Jardim. (OLIVEIRA, 2012, p. 23).

Destaca-se que as zonas rurais do município de Soure possuem fortes presenças de comunidades de vaqueiros marajoaras, camponês típico da região, os quais, como prática cultural, se deslocam constantemente pelas praias da costa litorânea no sentido zona ruralcidade-zona rural, principalmente em períodos conhecidos como inverno Amazônico e de fortes chuvas.

Em função destes deslocamentos que 2 (dois) jovens passarem três dias perdidos na Resexmar Soure em 2010. Segundo Pantoja (entrevista, 2019), que mora na fazenda tocantins, 
os jovens saíram da cidade de Soure entraram na área de reserva a partir da comunidade CajuUna caminhando pelas praias e objetivavam adentrar para a região de campos por meio de uma entrada na mata conhecida como varador próximo ao igarapé Mirinduba e assim chegar na fazenda tocantins.

Nesse contexto, os jovens percorreram no trajeto da viagem uma diversidade ecossistêmica, atravessando diversos cursos d'água na zona terrestre que sofrem fortes influencias de marés, sendo está uma questão fundamental para suas relações com o ambiente natural, em função da subida das marés, provocar dificuldades para se atravessar os cursos d'água, sendo que:

Com uma grande extensão de litoral na faixa equatorial, cerca de $90 \mathrm{~km}$ no total (área costeira e área ribeirinha), em sua maior parte com baixos níveis de ocupação e de difícil acesso, a Resexmar Soure se distingue por apresentar um complexo de ambientes aquáticos e alagáveis e de transição (ecótonos). Há praias selvagens, manguezais exuberantes (árvores com mais de 40m de altura), dunas, apicuns, pântanos salinos, igarapés, canais de maré, várzeas e matas de igapó regidos sob a forte e rica dinâmica das águas da foz da bacia Amazônica e das macromarés, com amplitude máxima de cerca de seis metros. (PLANO DE MANEJO RESEXMAR SOURE, 2018, p. 12).

Dessa maneira, a questão das marés tornou-se o primeiro obstáculo que os jovens enfrentaram, em virtude de ao tentarem atravessar um igarapé as correntezas os atingiram levando os seus alimentos de subsistências, pois nestas áreas:

A dinâmica da costa amazônica, com marés de até 6 metros de altura, junto à influência da foz do rio Amazonas, Baía de Marajó e Oceano Atlântico, moldam a diversidade da paisagem da Resexmar Soure. (PLANO DE MANEJO RESEXMAR SOURE, 2018, p. 11).

Lima (2019), um dos jovens que passou os três dias na área da Resexmar Soure, relata que tentarem atravessar o igarapé conhecido como glória e foram surpreendidos pela força das correntezas, em que:

Perdemos as coisas quando caímos no igarapé glória a maré me levou para fora eu estava com uma bota, calça cumprida e camisa mangas cumpridas, dei um jeito e tirei as botas a calça e camisa eu acho que devia estar uns 50 metros da beira quando comecei a nadar contra a maré, quando eu cansei aí eu afundei, foi quando meu pé deu na areia aí eu dei um impulso para a superfície dei mas umas quatro braçadas e cheguei até 
a beira, tomei um folego e atravessei para buscar o Duda. (LIMA, Entrevista, 2019).

Portanto, a partir deste incidente inicia-se a peleja dos jovens para chegarem ao seu destino, sem seus suprimentos alimentares que caíram na travessia do igarapé glória e exaustos passaram do local demarcado para entrarem, ficando assim, três dias caminhando na região até serem encontrados nas proximidades de uma fazenda conhecida como Araraquara.

Assim sendo, em meio a este contexto, os jovens estabeleceram estratégias de sobrevivências por meio dos saberes e relações socioambientais de experiências vividas como membros de famílias de vaqueiros marajoaras, que constroem seus cotidianos em meio a interação com ambientes naturais.

Os saberes ambientais de comunidade tradicionais, com os vaqueiros no arquipélago do Marajó, se traduzem nos modos simples de viver, desenvolvendo suas relações com o ambienta natural, constituindo resistência cultural, pertencimento e identidades com seus territórios (NAZARÉ; NASCIMENTO; PENHA, 2018).

Para Leff (2019) o saber ambiental impulsiona a produção do conhecimento, pois, é gerado na sistematização e no intercâmbio de prática culturais de experiências no uso e manejo de recursos naturais.

Nesta direção, que desenvolveram suas estratégias de sobrevivências que se relacionou com a coleta de frutas existentes na região da Resexmar Soure para se alimentaram, em dormir em dunas de areias para se protegerem de animais, beber água de raízes de vegetais e observar o ritmo das marés para verificar os melhores momentos de travessias, até serem encontrados.

\section{CONSIDERAÇÕES FINAIS}

Verificamos que os jovens sobreviveram a partir de suas práticas culturais tradicionais, as quais, vem sendo invisibilizadas pelo processo de modernização da sociedade, como vem apontando Leff (2018), o qual, destaca que o processo de modernização está causando a destruição dos ecossistemas de comunidades camponesas e indígenas.

Certamente que ao se adaptarem e interagirem com as dinâmicas estabelecidas pelo ambiente natural, nos três dias, os jovens dinamizaram sua relação com a natureza a partir de suas próprias experiências, em contraponto ao paradigma civilizacional tecnológico da sociedade moderna.

Assim sendo, conclui-se indicando que os saberes ambientais e relações socioambientais estão presentes no cotidiano das comunidades rurais do arquipélago do Complexitas - Rev. Fil. Tem., Belém, v. 4, n. 2 , p. 122-128, jul./dec. 2019 - ISSN: 2525-4154 
Marajó, sendo capazes de produzirem estratégias de sobrevivência, e afirmação de conhecimentos tradicionais.

\section{REFERÊNCIAS BIBLIOGRÁFICAS}

BRASIL. Sistema Nacional de Unidades de Conservação (SNUC). Brasília. 2000. Disponível em: http://www.icmbio.gov.br/sisbio/image s/stories/instrucoes_normativas/SNUC. pdf. Acesso em: 02 nov. 2019.

BRASIL. Plano de manejo da reserva extrativista marinha de Soure - Pa. Instituto chico mendes de conservação da biodiversidade (ICMBio). Brasília. 2018. Disponível em: http://www.icmbio.gov.br/portal/image s/stories/portaria_712_13ago2018_apro va_plano_de_manejo_rexes_soure.pdf. Acesso em 02 nov. 2019.

CRUZ, Miguel Evangelista Miranda da. Marajó Essa Imensidão de Ilha. São Paulo: M.E.M. Cruz, 1987.

GONÇALVES, Carlos Walter Porto. Os (des) caminhos do meio ambiente. São Paulo: Editora contexto, 2011.

LEFF, Enrique. Epistemologia ambiental. São Paulo: Cortez, 2007.

LEFF, Enrique. Ecologia, Capital $e$ Cultura: A Territorialização da Racionalidade Ambiental. Petrópolis: Vozes, 2018.
LEFF, Enrique. Saber Ambiental: Sustentabilidade, Racionalidade, Poder. Petrópolis: Vozes, 2019.

MIRANDA NETO, Manoel José de. Marajó: desafio da Amazônia. Belém: EDUFPA, 2005.

NAZARE, Mailson Lima; DO NASCIMENTO, Paula Mayara Rodrigues; PENHA, Rafael Santos. Grandes Projetos em Barcarena-Pa: Impactos Socioambientais Causados Pelas Atividades da Hydro Alunorte. Revista do Instituto Histórico e Geográfico do Pará, 2019. Disponível em:

http://ihgp.net.br/revista/index.php/revi sta. Acesso em: 02 nov. 2019.

OLIVEIRA, Ângela Maria Santos. Subsídios à gestão da reserva extrativista marinha de Soure-MarajóPará: uma análise dos problemas e conflitos socioambientais. Orientadora: Maria de Nazaré Ângelo-Menezes. 2012. 126 f. Dissertação (mestrado em Gestão Ambiental) Disponível em: http://www.repositorio.ufpa.br/jspui/bit stream/2011/9777/1/Dissertacao_Subsi diosGestaoReserva.pdf. Acesso em: 02 de nov. 2019.

NAZARÉ, M. L. Relações Socioambientais e Estratégias de Sobrevivência em Reserva Extrativista Marinha em Soure, Marajó.Complexitas - Rev. Fil. Tem. Belém, v. 4, n. 2, p. 122-128, jul./dec. 2019. Disponível em: http://www.periodicos.ufpa.br/index.php/complexitas/article/view/8079>. Acesso em: 30 de janeiro de 2020. 